Ophthalmologica 1982;185:121-124

\title{
Contents, Vol. 185, No. 3, 1982
}

Retinal Involvement in Familial Exudative Vitreoretinopathy

Miyakubo, H.; Inohara, N.; Hashimoto, K 125

Genetics of Lattice Degeneration of the Retina

Murakami, F.; Ohba, $\mathrm{N} \quad 136$

Perifoveal Capillary Network and Visual Prognosis in Diabetic Retinopathy

Tamura, T.; Tamura, M 141

Retinal Vascular Patterns in the Macula and the Perimacular Area in Premature andFull-Term

InfantsNishimura, M.; Taniguchi, Y 147

Radiation Effects on Retinoblastoma Successively Transplanted into Nude MouseEyesTotsuka, S.; Minoda, K 158

Experimental Central Serous Chorioretinopathy in Monkey Eyes: FluoresceinAngiographic FindingsYoshioka, H.; Katsume, Y.; Akune, $\mathrm{H}$ 168

Ohno, S.; Kato, F.; Matsuda, H.; Fujii, N.; Minagawa, T 187 T. The Role of Cytotoxic T Lymphocytes in the Pathogenesis of Vogt-Koyanagi-HaradaDiseaseMaezawa

N.; Yano

A.; Taniguchi

M.; Kojima

S $\quad 179$ 